\title{
The Correlation of Voiding Variables Between Non-Instrumented Uroflowmetery and Pressure-Flow Studies in Women With Pelvic Organ Prolapse
}

\author{
Elizabeth Mueller, ${ }^{1 *}$ John Wei, ${ }^{2}$ Ingrid Nygaard, ${ }^{3}$ Linda Brubaker, ${ }^{1}$ Ed Varner, ${ }^{4}$ Anthony Visco, ${ }^{5}$ \\ Geoffrey W. Cundiff, ${ }^{6}$ Anne M. Weber, ${ }^{7}$ Chiara Ghetti, ${ }^{8}$ and Karl Kreder ${ }^{9}$ \\ ${ }^{1}$ Departments of Urology and Obstetrics and Gynecology, Loyola University Medical Center, Maywood, Illinois \\ ${ }^{2}$ Department of Urology, University of Michigan, Ann Arbor, Michigan \\ ${ }^{3}$ Department of Obstetrics and Gynecology, University of Utah, Salt Lake City, Utah \\ ${ }^{4}$ Department of Obstetrics and Gynecology, University of Alabama, Birmingham, Alabama \\ ${ }^{5}$ Department of Obstetrics and Gynecology, University of North Carolina at Chapel Hill, Chapel Hill, North Carolina \\ ${ }^{6}$ Department of Obstetrics and Gynecology, Johns Hopkins University School of Medicine, Baltimore, Maryland \\ ${ }^{7}$ National Institute for Child Health and Human Development, National Institute of Health, Bethesda, Maryland \\ ${ }^{8}$ Department of Obstetrics, Gynecology, and Reproductive Sciences, Magee Women's Hospital, Pittsburgh, Pennsylvania \\ ${ }^{9}$ Department of Urology, University of Iowa Carver College of Medicine, Iowa City, Iowa
}

\begin{abstract}
Aims: To (1) correlate peak and maximum flow rates from non-instrumented flow (NIF) and pressure-flow studies (PFS) in women with pelvic organ prolapse (POP); (2) measure the impact of voided volume and degree of prolapse on correlations. Methods: We compared four groups of women with stages II-IV POP. Groups 1 and 2 were symptomatically stress continent women participating in the colpopexy and urinary reduction efforts (CARE) trial; during prolapse reduction before sacrocolpopexy, Group $1(\mathrm{n}=67)$ did not have and Group $2(\mathrm{n}=84)$ had urodynamic stress incontinence (USI). Group $3(\mathrm{n}=74)$ and Group 4 participants $(\mathrm{n}=73)$, recruited specifically for this study, had stress urinary incontinence (SUI) symptoms. Group 3 planned sacrocolpopexy. Group 4 planned a different treatment option. Participants completed standardized uroflowmetry and pressure voiding studies. Results: Subjects' median age was 61 years; median parity $3 \%$ and $80 \%$ had stage III or IV POP. Based on the Blaivas-Groutz nomogram, 49\% of all women were obstructed. NIF and PFS peak and average flow rates had low correlations with one another $(0.31, P<0.001$ and $0.35, P<0.001$, respectively). When NIF and PFS voided volumes were within $25 \%$ of each other, the peak and average flow rate correlations improved $(0.52, P<0.001$ and 0.57 , $P<0.001$, respectively). As vaginal prolapse increased, correlations between NIF and PFS peak and average flow rates decreased. Conclusion: Peak and average flow rates are highly dependent on voided volume in women with prolapse. As the prolapse stage increases, correlations between NIF and PFS variables decrease. Neurourol. Urodynam. 27:515-521, 2008. (c) 2008 Wiley-Liss, Inc.
\end{abstract}

Key words: non-instrumented uroflow study; obstruction; pelvic organ prolapse; pressure-flow study; urodynamics; voiding

\section{INTRODUCTION}

Women with pelvic organ prolapse (POP) may experience a variety of urinary symptoms, ranging from urinary leakage to obstructive voiding. Obstructive symptoms are common in prolapse and may reflect patho-physiologic obstruction during the voiding phase of micturition. Symptoms suggestive of obstruction, such as a decreased force of stream, urinary hesitancy, straining and need to manually manipulate prolapse occur in $14-76 \%$ of women with prolapse $e^{1,2}$ and these voiding difficulties have been associated with increasing severity of prolapse. ${ }^{3}$ These clinical observations lend credence to the hypothesis that the urethra is "functionally obstructed" in advanced stages of prolapse. ${ }^{4}$

The ability to diagnose bladder outlet obstruction (BOO) may assist the clinician in determining whether obstructive symptoms are attributable to prolapse. The most common office-based measures for BOO are simple non-instrumented uroflowmetry study (NIF) and an assessment of post-void residual volume (PVR). A NIF requires a woman to urinate into a device that measures the weight of the fluid by time. The output is typically a curve of flow rate $(\mathrm{ml} / \mathrm{sec})$ versus time.
The area under the curve is the total volume of the urination. Women with prolapse generally have larger PVR's and lower urinary flow rates by NIF compared to women with urinary incontinence and no prolapse..$^{5}$ The pressure-flow study (PFS) is performed by urinating into a flow device with a small catheter placed transurethrally into the bladder so that vesical pressure can be measured simultaneously. PFS provide a flow curve similar to uroflowmetry in addition to a measure

No conflict of interest reported by the author(s).

Heinz Koebl led the review process.

Grant sponsor: National Institute of Child Health and Human Development; Grant numbers: U01 HD41249, U10 HD41268, U10 HD41248, U10 HD41250, U10 HD41261, U10 HD41263, U10 HD41269, U10 HD41267.

${ }^{*}$ Correspondence to: Elizabeth Mueller, MD, Departments of Urology and Obstetrics and Gynecology, Loyola University Medical Center, 2160 S. First Avenue, Building 103, Room 1004, Maywood, IL 60153.

E-mail: emuelle@lumc.edu

Received 30 August 2007; Accepted 7 January 2008

Published online 12 June 2008 in Wiley InterScience

(www.interscience.wiley.com)

DOI 10.1002/nau.20568 
of the vesical pressure. The transurethral catheter lowers the peak flow rates obtained in women with and without BOO. ${ }^{4}$

Among men with benign prostatic hyperplasia where BOO is highly prevalent, obstructed voiding is differentiated from non-obstructed voiding by nomograms that use the PFS values of peak flow $\left(\mathrm{Q}_{\max }\right)$ and detrusor pressure at peak flow ( $\left.\mathrm{P}_{\text {det }} \mathrm{Q}_{\max }\right) .^{6-8}$ A nomogram specifically for women with symptoms of BOO, the Blaivis-Groutz nomogram, uses O $_{\max }$ from the NIF and the maximum detrusor pressure ( $\left.\mathrm{P}_{\text {detmax }}\right)$ from the PFS. ${ }^{8}$ The NIF $\mathrm{O}_{\max }$ was preferred by the authors because many of the obstructed subjects had low peak flow rates due to the transurethral catheter. The $\mathrm{P}_{\text {detmax }}$ was preferred to the $\mathrm{P}_{\text {det }} \mathrm{O}_{\max }$ because they were found to not be statistically different and in cases of retention, no value for $\mathrm{P}_{\text {det }} \mathrm{O}_{\max }$ could be obtained.

The relationship between peak and average flow rates obtained during NIF and PFS is largely unstudied in women with prolapse. It is unknown whether the urethral catheter stents the potentially obstructed urethra during voiding in a PFS in women with prolapse, thereby underestimating the frequency and/or degree of functional urethral obstruction associated with prolapse.

The primary aim of this study was to investigate the relationship of urine flow rates during NIF and PFS in women with POP. We also wanted to better understand how the voided volume and degree of prolapse influenced flow variables obtained during NIF and PFS. For example, some evidence suggests that low voided volumes (e.g., $<150 \mathrm{ml}$ ) negatively impact the reliability of test results. ${ }^{9}$ To achieve these aims, we conducted a prospective supplementary study to the NIH/NICHD's Pelvic Floor Disorders Network (PFDN) colpopexy and urinary reduction efforts (CARE) trial. ${ }^{10}$ The CARE trial enrolled women without symptoms of stress incontinence (SUI) undergoing sacrocolpopexy for POP with the primary aim of determining if adding a Burch colposuspension at the time of prolapse surgery would reduce symptoms of stress incontinence post-operatively. For this supplementary study, we also enrolled women with prolapse and symptoms of SUI. This provided a sample of women with prolapse and a broad spectrum of urinary symptoms in which to study voiding parameters during NIF and PFS.

\section{METHODS}

This study was approved by the Institutional Review Board of each participating center. All participants signed informed consent before any study procedures were done. Participants included 298 women with stages II-IV POP, divided into four groups, as follows:

(1) Group 1, stress continent: 67 women randomly selected from women enrolled in the colpopexy and urinary reduction efforts (CARE) trial ${ }^{10}$ who were defined as stress continent and demonstrated no urodynamic stress incontinence (USI) with prolapse reduction.

(2) Group 2, occult SUI: 84 women randomly selected from women enrolled in the CARE trial who were defined as stress continent and demonstrated USI with prolapse reduction (i.e., urinary leakage from the urethral meatus with cough or Valsalva with the prolapse reduced).

(3) Group 3, stress incontinent: 74 women who met the same eligibility criteria for the CARE trial (i.e., they were planning sacrocolpopexy for prolapse) except they were stress incontinent.
(4) Group 4, stress incontinent: 73 women who had prolapse and SUI symptoms but they were not planning sacrocolpopexy.

CARE subjects were considered stress continent (and thus eligible for CARE) if they responded "never" or "rarely" to six of the stress incontinence questions from the Medical, epidemiological, and social aspects of aging (MESA) questionnaire (coughing hard, sneezing, lifting, bending, laughing, and walking briskly or jogging); and stress incontinent if they responded "sometimes" or "usually" to any of these same MESA questions. ${ }^{11}$ Women enrolled in the CARE trial and those recruited for this supplementary study underwent identical standardized urodynamics procedures and pelvic organ prolapse quantification (POP-O) ${ }^{12}$ examination by certified research nurses.

For this supplementary study, subjects were included only if they answered affirmatively to either of two questions about seeing or feeling a vaginal bulge. ${ }^{13}$ Additionally, women in groups $1-3$ were included only if POP-O point $\mathrm{Aa}$ was located $1 \mathrm{~cm}$ above the hymen or lower, while women in group 4 did not have this requirement.

The urodynamics protocol, including quality control measures, has been described in detail elsewhere. ${ }^{14}$ In brief, participants underwent NIF followed by non-fluoroscopic urodynamic studies with external water pressure transducers. Women were instructed to come to this appointment with a comfortably full bladder. Non-instrumented uroflowmetry was done with participants in a seated position. Post-void residual (PVR) urine volume was obtained by catheterization within 15 min of NIF.

The same multi-channel urodynamic recorder was used for all urodynamic studies. The cystometrogram was performed with participants seated at a $45^{\circ}$ angle, using $\leq 8$ French lumen external water transducer catheters that were zeroed to atmospheric pressure at the superior level of the symphysis pubis prior to insertion. Intravesical pressure $\left(\mathrm{P}_{\mathrm{ves}}\right)$, intraabdominal pressure $\left(\mathrm{P}_{\mathrm{abd}}\right)$, and subtracted detrusor pressure $\left(\mathrm{P}_{\text {det }}\right)$ were continuously recorded. The bladder was filled with room temperature sterile saline or water at $50 \mathrm{ml} / \mathrm{min}$. A rectal catheter was used to estimate intra-abdominal pressure. During filling cystometry Valsalva and cough leak point pressures were obtained at $300 \mathrm{ml}$ and maximum cystometric capacity (MCC) with the prolapse reduced by one of three methods that were randomized to the center performing the study.

The PFS was done with the prolapse reduction method removed. The subject was instructed to bear down or cough to encourage the prolapse to become maximal again prior to voiding. Urethral relaxation was not documented during the pressure-flow voiding study.

We assessed voiding obstruction using the parameters of non-instrumented peak flow rate $\left(\mathrm{O}_{\max } \mathrm{NIF}\right)$ and maximum detrusor pressure ( $\mathrm{P}_{\text {detmax }}$ ) from the PFS as outlined by Blaivas and Groutz. ${ }^{4}$ The void was defined as obstructed when values fell outside of the "unobstructed area" on the nomogram.

Urinary retention was defined as voiding $<75 \%$ of total bladder volume. Total bladder volume was defined as the voided volume plus the PVR. Maximum bladder capacity was defined as the volume during filling cystometry at which women stated they could no longer delay a trip to the bathroom.

\section{Statistical Analysis}

The four groups were compared by either a chi-square test when the measure was discrete or by an analysis of variance 
when the measure was continuous. The non-parametric paired sign test was used to compare differences between paired data. Urodynamic data for the four groups were also compared after adjustment for age as a continuous measure and prior surgery for prolapse or incontinence as a dichotomous measure. Correlations were computed to assess associations between measures. With approximately 70 subjects per group there is greater than $80 \%$ power to identify a difference of $0.5 \mathrm{SD}$ when testing a continuous outcome or a difference of $25 \%$ when testing a dichotomous outcome at a $5 \%$ level of significance.

Prior to performing the scatter plots, we restricted the data to voided volumes either $>150$ or $>50 \mathrm{ml}$ (depending on the analysis) for both NIF and PFS. In addition, we performed a box plot and whisker graphs and removed data points that were "outliers." Data for the scatter plots were analyzed using SPSS software (Chicago, IL).

\section{RESULTS}

Demographic characteristics and physical examination findings of the four groups, shown in Table I, were similar except women with occult SUI (Group 2) were older $(P=0.022)$ and the proportion of women that had undergone previous incontinence surgery differed between the groups $(P<0.001)$.

Across the different groups, peak flow rate, average flow rate, and PVR did not differ significantly based on the presence of SUI symptoms or urodynamic diagnosis of stress incontinence (Table II). Peak flow rates were higher in the PFS compared to the NIF studies. Comparing values obtained from NIF versus PFS, correlations between peak and average flow rates were moderate for stress continent women (Group 1; $\mathrm{r}=0.42, P=0.002$; and $\mathrm{r}=0.43, P=0.002$, respectively); correlations were lower in the other two groups. PVR measurements obtained during NIF and PFS were not significantly correlated. Approximately 50\% of women were "obstructed" based on the Blaivas-Groutz nomogram independent of continence status.

Sixty-eight (23\%) of women were unable to void for one of the studies. Only the remaining women with both NIF and PFS voided volumes $>0 \mathrm{ml}$ were included in the correlation analyses. Total bladder volume was higher in PFS compared to
$\mathrm{NIF}(431 \pm 149 \mathrm{ml}$ vs. $316 \pm 227 \mathrm{ml}, P<0.001, \mathrm{n}=244)$, as were mean voided volumes $(386 \pm 174 \mathrm{ml}$ vs. $246 \pm 202 \mathrm{ml}$, $P<0.001, \mathrm{n}=239$ ). Peak flow rates obtained during PFS were higher than those obtained by NIF (22 $\pm 16 \mathrm{vs} .18 \pm 10 \mathrm{ml} / \mathrm{sec}$, $P=0.001, \mathrm{n}=230)$, average flow rates obtained during PFS were slightly lower than those obtained by NIF $(8 \pm$ 4 vs. $9 \pm 6 \mathrm{ml} / \mathrm{sec}, P=0.02, \mathrm{n}=215$ ).

As seen in Table III, correlations between NIF and PFS peak and average flow rates varied from 0.26 to 0.57 based on the conditions specified. The strongest correlation was seen for PFS and NIF voided volumes within $25 \%$ of one another: the mean total bladder volume was similar $(466 \pm 196 \mathrm{ml}$ vs. $471 \pm 194 \mathrm{ml}, P=0.68)$ although mean voided volumes by PFS were slightly higher than by NIF $(404 \pm 215 \mathrm{ml}$ vs. $383 \pm 188 \mathrm{ml}, P=0.04)$. In contrast to the findings for the entire group, peak and average flow rates were higher by NIF compared to PFS (peak: $22 \pm 9$ vs. $20 \pm 14 \mathrm{ml} / \mathrm{sec}, P=0.008$, $\mathrm{n}=55$; average: $11 \pm 6$ vs. $7 \pm 4 \mathrm{ml} / \mathrm{sec}, P<.001$ ). Restricting the analysis to voided volumes by NIF and PFS $>150 \mathrm{ml}$ did not improve the correlations from the original analyses (i.e., analyses excluding only those who could not void by NIF and PFS). Correlations in peak flow rates decreased as the maximal vaginal descent increased.

In order to better understand the relationship of flow rates and voided volume, we performed scatter plots of NIF and PFS flow rates versus their respective voided volumes. Box plots of NIF and PFS peak and average flow rates were performed to remove outliers (Fig. 1). For women who voided $\geq 150 \mathrm{ml}$, the majority of the outliers in peak flow rates were seen in the flow measurements taken during the PFS and there were none in NIF. Peak flow rate outliers were $\geq 58 \mathrm{ml} / \mathrm{sec}$. Outlier values for PFS and NIF average flow rates were $\geq 21$ and $25 \mathrm{ml} / \mathrm{sec}$, respectively.

For the first graphical analysis we limited the data to women who voided $\geq 150 \mathrm{ml}$ for each of the studies. For the second analysis we limited the data to women who voided $\geq 50 \mathrm{ml}$ for each of the studies.

As demonstrated in Figure 2, in women who voided $\geq 150 \mathrm{ml}$, NIF and PFS peak flow rates increased with increasing voided volumes and is represented by the following linear equations,

$$
\begin{aligned}
& \text { NIF : }{ }_{-\max } \mathrm{ml} / \mathrm{sec}=0.023 \text { (Voided Volume) }+13.5 \mathrm{ml} / \mathrm{sec}, \mathrm{n}=115, \mathrm{r}^{2}=0.23 \\
& \text { PFS : } \underline{-}_{\max } \mathrm{ml} / \mathrm{sec}=0.023 \text { (Voided Volume) }+9.5 \mathrm{ml} / \mathrm{sec}, \mathrm{n}=115, \mathrm{r}^{2}=0.15
\end{aligned}
$$

\begin{tabular}{|c|c|c|c|c|}
\hline Characteristic & $\begin{array}{l}\text { Stress continent } \\
\text { Group } 1(n=67)\end{array}$ & $\begin{array}{c}\text { Occult SUI } \\
\text { Group } 2(n=84)\end{array}$ & $\begin{array}{l}\text { Stress incontinent } \\
\text { Group } 3(n=74)\end{array}$ & $\begin{array}{l}\text { Stress incontinent } \\
\text { Group } 4(\mathrm{n}=73)\end{array}$ \\
\hline Age in years: mean $\pm S D$ & $58 \pm 10$ & $62 \pm 11$ & $57 \pm 14$ & $60 \pm 14$ \\
\hline Parity: median (range) & $2(1-8)$ & $3(1-7)$ & $3(0-8)$ & $3(0-7)$ \\
\hline \multicolumn{5}{|l|}{ POP-O stage: $n(\%)$} \\
\hline Stage II & $8(12 \%)$ & $11(13 \%)$ & $10(13.5 \%)$ & $32(44 \%)$ \\
\hline Stage III & $48(72 \%)$ & $61(73 \%)$ & $54(73 \%)$ & $36(49 \%)$ \\
\hline Stage IV & $11(16 \%)$ & $12(14 \%)$ & $10(13.5 \%)$ & $5(7 \%)$ \\
\hline Prior surgery for POP: $\mathrm{n}(\%)$ & $18(27 \%)$ & $35(42 \%)$ & $30(41 \%)$ & $19(26 \%)$ \\
\hline Prior surgery for UI: $\mathrm{n}(\%)$ & $0(0 \%)$ & $8(10 \%)$ & $19(26 \%)$ & $16(22 \%)$ \\
\hline Maximum anterior prolapse $(\mathrm{cm}):$ mean $\pm S D$ & $+3.0 \pm 2.5$ & $+3.2 \pm 2.6$ & $+2.8 \pm 2.8$ & $+1.4 \pm 2.5$ \\
\hline Maximum vaginal descent $(\mathrm{cm}):$ mean $\pm S D$ & $+3.6 \pm 2.2$ & $+3.9 \pm 2.2$ & $+3.6 \pm 2.4$ & $+1.9 \pm 2.2$ \\
\hline
\end{tabular}

TABLE I. Demographic and Clinical Characteristics of 298 Women With Prolapse, Grouped by Stress Continence Status

More women in Groups 2, 3 and 4 each had prior surgery for UI than in Group $1(P<0.001)$.

Maximum anterior prolapse based on point $\mathrm{Ba}$ from POP-O, maximal vaginal descent based on most distal POP-O point.

There are no statistically significant differences between groups except for the following characteristics.

Women in Group 2 are older than the other three groups $(P=0.02)$. 
TABLE II. Voiding and Urodynamic Parameters by Cohort

\begin{tabular}{|c|c|c|c|c|}
\hline Characteristic & $\begin{array}{c}\text { No SUI } \\
\text { Group } 1(n=67)\end{array}$ & $\begin{array}{l}\text { Occult SUI G } \\
\text { roup } 2(n=84)\end{array}$ & $\begin{array}{c}\text { Overt SUI } \\
\text { Group } 3(n=74)\end{array}$ & $\begin{array}{l}\text { Overt SUI } \\
\text { Group } 4(n=73)\end{array}$ \\
\hline \multicolumn{5}{|l|}{$\underline{\mathrm{O}}_{\max }$ mean $\pm \mathrm{SD}(\mathrm{ml} / \mathrm{sec})$} \\
\hline NIF & $17 \pm 10$ & $18 \pm 11$ & $17 \pm 10$ & $20 \pm 11$ \\
\hline PFS & $21 \pm 14$ & $20 \pm 14$ & $23 \pm 17$ & $24 \pm 15$ \\
\hline NIF-PFS correlation, $r$ ( $P$-value $)$ & $0.42(0.002)$ & $0.26(0.03)$ & $0.40(0.003)$ & $0.19(0.17)$ \\
\hline \multicolumn{5}{|l|}{$\mathrm{Q}_{\mathrm{avg}}$ mean $\pm \mathrm{SD}(\mathrm{ml} / \mathrm{sec})$} \\
\hline NIF & $8 \pm 6$ & $9 \pm 6$ & $8 \pm 6$ & $10 \pm 6$ \\
\hline PFS & $8 \pm 5$ & $8 \pm 4$ & $7 \pm 4$ & $9 \pm 5$ \\
\hline NIF-PFS correlation, $r$ ( $P$-value $)$ & $0.44(0.002)$ & $0.28(0.02)$ & $0.43(0.003)$ & $0.28(0.05)$ \\
\hline \multicolumn{5}{|l|}{ PVR median (range) $\mathrm{ml} / \mathrm{sec}$} \\
\hline NIF & $50(0-520)$ & $50(0-600)$ & $40(0-276)$ & $60(2-425)$ \\
\hline PFS & $33(0-381)$ & $25(0-821)$ & $30(0-390)$ & $32(0-529)$ \\
\hline NIF-PFS correlation, $r$ ( $P$-value) & $0.04(0.76)$ & $0.03(0.82)$ & $0.32(0.01)$ & $0.10(0.45)$ \\
\hline $\begin{array}{l}\text { Obstruction on nomogram n } \\
(\%)\end{array}$ & $31(48 \%)$ & $38(51 \%)$ & $25(41 \%)$ & $33(58 \%)$ \\
\hline
\end{tabular}

A similar relationship was found for average flow rates in women who voided $\geq 150 \mathrm{ml}$. The scatter plot for average flow rates versus voided volume is similar and is represented by the following linear equations:

NIF $: Q_{\text {avg }} \mathrm{ml} / \mathrm{sec}=0.011$ (Voided Volume) $+6.6 \mathrm{ml} / \mathrm{sec}, \mathrm{r}^{2}=0.17$ PFS : ${ }_{-a v g} \mathrm{ml} / \mathrm{sec}=0.012$ (Voided Volume) $+2.8 \mathrm{ml} / \mathrm{sec}, \mathrm{r}^{2}=0.21$

we repeated the graphical analysis and included women who voided $\geq 50 \mathrm{ml}$ for both studies and found that the linear relationship between the PFS peak flow rate and voided volume was unchanged but the relationship between the NIF and voided volume changed (Fig. 3):

\section{DISCUSSION}

We previously demonstrated a $60 \%$ rate of urinary obstruction in women with stage II-IV POP using the Blaivas-Groutz obstruction nomogram for women. ${ }^{15}$ We found that symptoms of obstruction and retention correlated poorly with urodynamic findings of obstruction. We also found that women with prolapse and USI had the same urine flow rates as women with prolapse without USI. We hypothesized that this occurs because stress incontinence results from a loss of sphincteric integrity and during urination the sphincter is open.

The Blaivas-Groutz nomogram was developed from 50 women with symptomatic BOO and included 10 women

NIF : $\mathrm{O}_{\max } \mathrm{ml} / \mathrm{sec}=0.031$ (Voided Volume) $+9.4 \mathrm{ml} / \mathrm{sec}, \mathrm{n}=169, \mathrm{r}^{2}=0.19$

PFS : $\underline{-}_{\max } \mathrm{ml} / \mathrm{sec}=0.023$ (Voided Volume) $+9.5 \mathrm{ml} / \mathrm{sec}, \mathrm{n}=169, \mathrm{r}^{2}=0.40$

The results for average flow rates demonstrate a minimal change in the slope and $y$-intercept; however, the lines do not intersect at any volume. with severe genital prolapse. As noted in the introduction, the nomogram uses the peak flow from the NIF and the $\mathrm{P}_{\text {det }} \mathrm{O}_{\max }$ from the PFS. We questioned how peak flows obtained in a NIF

NIF : $\mathrm{O}_{\text {avg }} \mathrm{ml} / \mathrm{sec}=0.015$ (Voided Volume) $+4.5 \mathrm{ml} / \mathrm{sec}, \mathrm{n}=169, \mathrm{r}^{2}=0.28$

PFS : $\underline{Q}_{\text {avg }} \mathrm{ml} / \mathrm{sec}=0.012$ (Voided Volume) $+2.6 \mathrm{ml} / \mathrm{sec}, \mathrm{n}=169, \mathrm{r}^{2}=0.34$

TABLE III. Correlations Between NIF and PFS Flow Ratesa

\begin{tabular}{llc}
\hline $\begin{array}{l}\text { Peak flow rate } \\
\text { r-value, } P \text {-value, } n\end{array}$ & \multicolumn{1}{c}{ Condition } & Average flow rate r-value, $P$-value, $n$ \\
\hline $0.31,<0.001,230$ & All & $0.35,<0.001,215$ \\
$0.52,<0.001,56$ & Voided volumes within 25\% & $0.57,<0.001,54$ \\
$0.32,<0.001,174$ & Voided volumes NOT within $25 \%$ & $0.30,<0.001,161$ \\
$0.34,<0.001,135$ & Voided volumes NIF and PFS both $>150 \mathrm{ml}$ & $0.41,<0.001,129$ \\
$0.40,0.004,56$ & Maximal vaginal descent $<2 \mathrm{cmb}$ & $0.33,0.02,51$ \\
$0.29,0.006,91$ & Maximal vaginal descent $\geq 2$ and $<4 \mathrm{~cm}^{\mathrm{b}}$ & $0.42,<0.001,85$ \\
$0.26,0.078,46$ & Maximal vaginal descent $\geq 4$ and $<6 \mathrm{~cm}^{\mathrm{b}}$ & $0.29,0.06,43$ \\
$0.20,0.22,41$ & Maximal vaginal descent $\geq 6 \mathrm{~cm}^{\mathrm{b}}$ & $0.26,0.125,36$
\end{tabular}

${ }^{\text {aThis }}$ analysis was restricted to woman who could void for both studies.

${ }^{b}$ Maximal vaginal descent is defined as most distal POP-Q point. 


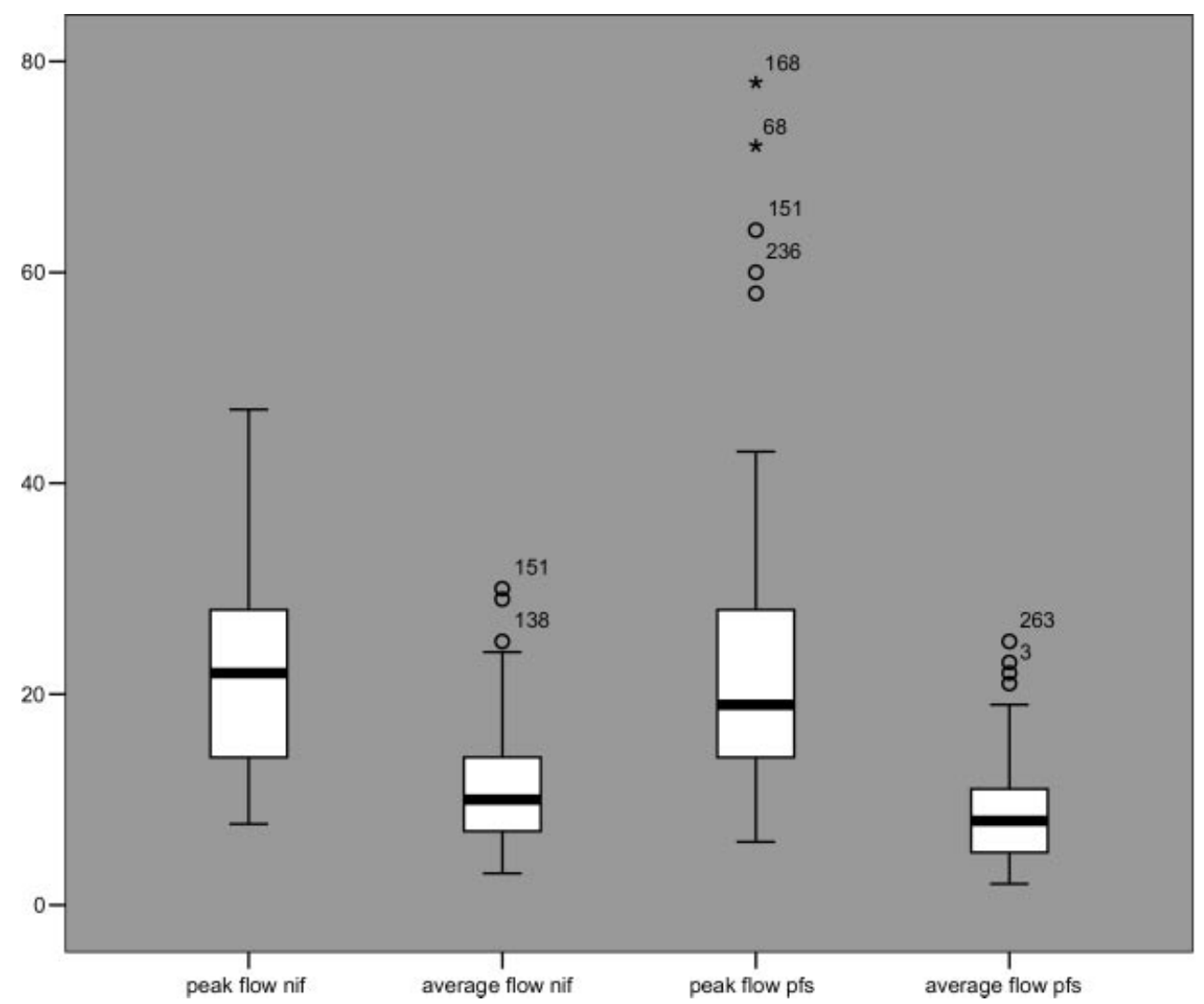

Fig. 1. Boxplot of NIF and PFS Peak and average flow rates $(\mathrm{cc} / \mathrm{sec})$ for women who voided a minimum of $150 \mathrm{~cm}^{3}$ for each study.

compare to those obtained in the same woman during PFS. To our knowledge, this is the first study to look at the correlation between peak and average flows obtained during the NIF and PFS in women with prolapse.
We saw moderate correlations in peak and average flow rates between NIF and PFS. ${ }^{8}$ It is known that NIF and PFS flow rates increase with increasing voided volumes and that when voided volumes are low, flow rates can be unreliable. ${ }^{9}$ We

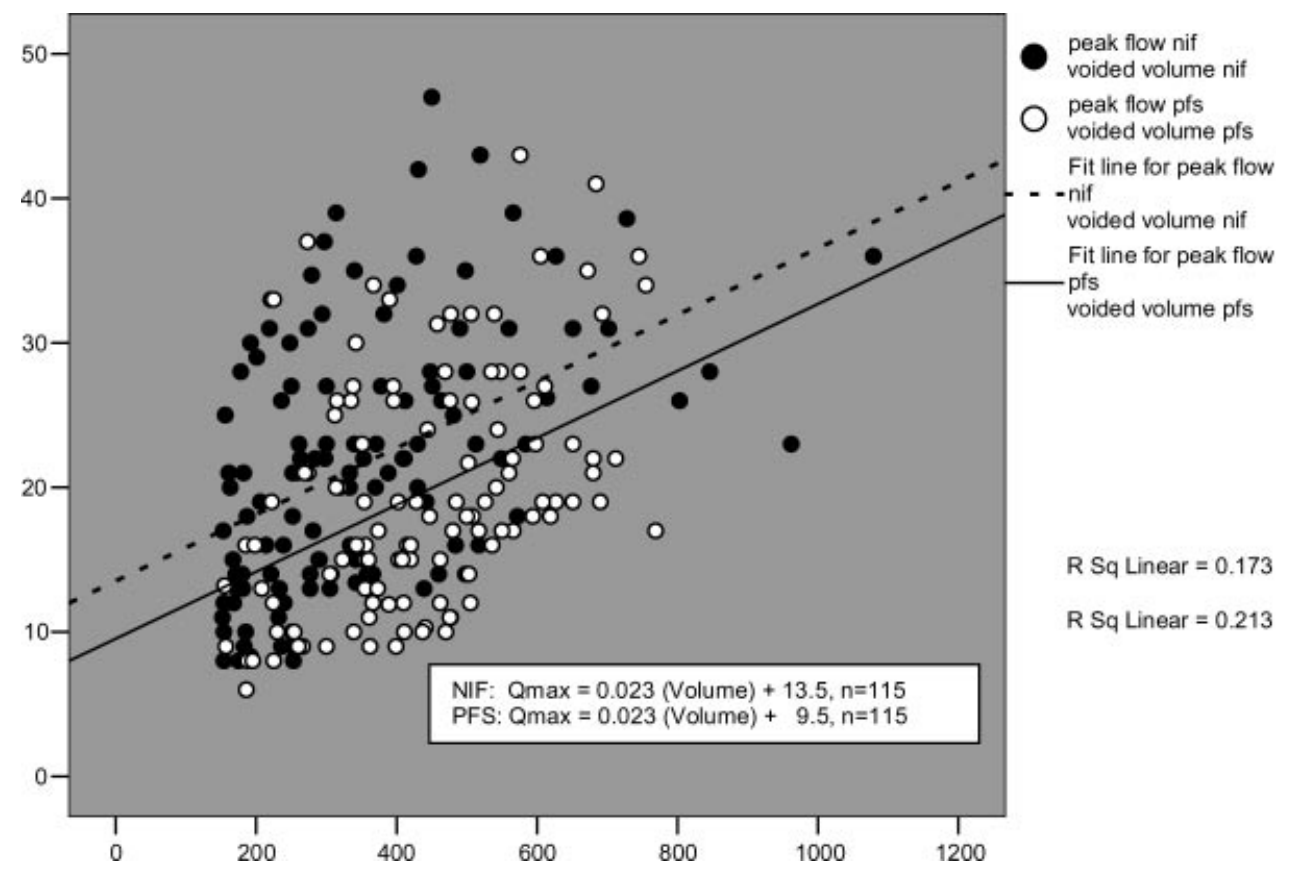

Fig. 2. Peak flow versus voided volume (NIF and PFS voided volume $\geq 150 \mathrm{~cm}^{3}$, outliers out). 


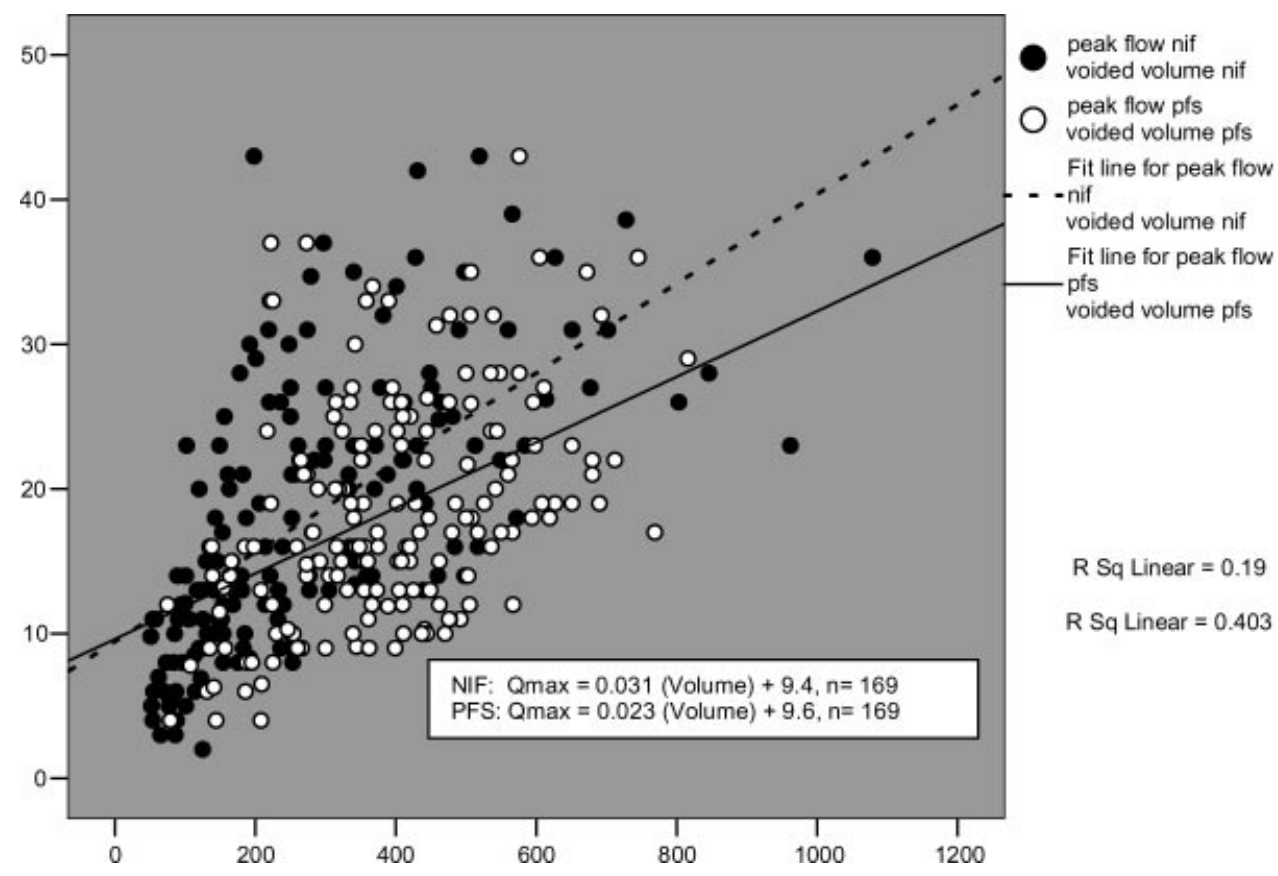

Fig. 3. Peak flow versus voided volume (NIF and PFS voided volume $\geq 50 \mathrm{~cm}^{3}$, outliers out).

therefore performed a sub analysis of women with voided volumes for NIF and PFS over $150 \mathrm{ml}$, a cutoff that has been previously reported to be pertinent; ${ }^{16}$ however, the correlations did not improve. It has been suggested that it may be more appropriate to compare NIF and PFS from voids with similar voided volumes rather than using an arbitrary cutoff of $150 \mathrm{ml} .{ }^{17}$ We observed the highest correlations in peak flow rates $(r=0.52)$ and average flow rates $(r=0.57)$ when comparisons between NIF and PFS studies were limited to those voids with voided volumes within $25 \%$ of each other. As the maximal vaginal descent increased the correlation between NIF and PFS peak and average flows decreased and with descent $>4 \mathrm{~cm}$ there was no statistically significant $P$ values associated with the flow rate correlations.

As previously mentioned, the difficulty with flow rate correlations is that they are confounded by differences in voided volumes between the NIF and PFS studies. Women had higher total bladder and voided volumes during PFS compared to NIF. PFS were performed to MCC while women were instructed to arrive with a comfortably full bladder for the NIF. There is also a significant amount of individual variation in flow rates and bladder volumes for "normal" women and previous authors have recommended the need for repeated measurements to obtain a mean value ${ }^{18,19}$ Given these limitations, it is not surprising that correlations between NIF and PFS flow rates in this study are generally low and improve when voided volumes are similar.

We found higher values for peak flow rates in the PFS compared to the NIF when we included all women who could void for both studies. This is contrary to previous observations made by others. ${ }^{4,16}$ The observation of higher values for peak flow rates in the PFS compared to the NIF in this study is explained by differences in the voided volumes. When the voided volumes were within $25 \%$ of each other, we found that NIF peak and average flow rates were higher than those obtained during the PFS for similar voided volumes, as previously observed in women with and without prolapse l,16,17 and presumably due to lack of instrumentation during NIF.

Prior to performing scatter plots of flow rates and voided volumes we removed flow rate outliers. The majority of the outliers occurred in peak flow PFS measurements (outlier defined as $\geq 58 \mathrm{ml} / \mathrm{sec}$ ) and were considered physiologically abnormal when compared to median peak flow rates for NIF in urodynamically "normal" women of $23 \mathrm{ml} / \mathrm{sec}^{20}$ The scatter plots provide some important insights about NIF and PFS flow rates in women with prolapse. The first is that for similar voided volumes $\geq 150 \mathrm{ml}$, NIF peak and average flow rates are higher than PFS. The presence of the catheter appears to obstruct urine flow in women with prolapse as it does in women without prolapse. When the voided volumes are between 50 and $150 \mathrm{ml}$, the PFS peak flow to voided volume linear equation remains unchanged; however the NIF peak flow to voided volume linear regression changes. We hypothesize that this occurs due to the presence of the catheter in the PFS study that while obstructing also acts to "stent" the urethra resulting in less urethral resistance. The detrusor pressures are thus transmitted to the urine flow allowing the small amount of urine volume to reach its peak faster before the volume is excreted. Conversely, during NIF a portion of the detrusor pressure is applied to overcoming urethral resistance and as a result less force is available to the smaller voided volume and as a result, peak flow rates are not as high. At higher volumes the urethral resistance is overcome in the early part of urination and all of the detrusor pressure is applied to the urine stream so we do not observe this phenomenon.

In women who voided $\geq 150 \mathrm{ml}$ we find that peak flow rates seen with NIF and PFS increased $2.3 \mathrm{ml} / 100 \mathrm{ml}$ in women with prolapse. Jorgensen found that NIF peak flow increased linearly by $5.6 \mathrm{ml} / 100 \mathrm{ml}$ in women without prolapse. ${ }^{21}$ This further supports previous studies that reported reduced flow rates in women with prolapse. ${ }^{22}$ 
Sixty-eight women were unable to void for both the NIF and PFS studies. Of the 68 who could not urinate, the majority (69\%) could not void during the PFS but could during the NIF. Multiple factors can contribute to being unable to urinate with the catheter in place including obstruction from the prolapse and or catheter, inability to initiate urination during the PFS due to the laboratory setting and inability to relax the pelvic floor. Unfortunately, this study did not obtain measures of urethral function during attempts to urinate. Although a previous study in women who had advanced prolapse and PFS with the prolapse reduced and unreduced demonstrated urethral quieting by concentric needle electromyography giving credence to the theory of urethral kinking as a mechanism for obstructive voiding in women. ${ }^{23}$

One limitation of this study is that the pooled analysis shows linear $r^{2}$ values that are low. The square of the correlation coefficient $\left(r^{2}\right)$ is considered a measure of linearity and also describes how much of the change in peak and average flow can be attributed to the changes in voided volume. Since only $15-40 \%$ of the difference in peak and average flow with NIF and PFS are explained by differences in voided volume, other parameters need to be evaluated. In this pooled analysis, contributing factors include not only the within-subject variation of flow rates and voided volumes but the more significant between-subject variation which results in fivefold higher standard deviations in flow rates. $^{19}$

The use of voiding studies to direct clinical care in women with prolapse is uncertain. What additional value can be gained from voiding studies for women who plan treatment of POP? Clearly routine voiding studies play no role in discriminating which woman has storage phase abnormalities, such as stress incontinence. Thus it is illogical to use a voiding study phase to "triage" the stress incontinence procedure. ${ }^{15}$ The classic use of voiding studies to diagnose obstruction is most likely unnecessary in this group since the elevated urethral pressures caused by "urethral kinking" resolve with prolapse reduction and the elevated PVR nearly universally returns to the normal range. ${ }^{23,24}$ In addition, the obstruction caused by prolapse is often temporary and resolves when the women lies down or reduces the prolapse manually. This is certainly not the case in men with BOO due an enlarged prostate. This finding may explain why advanced stages of prolapse are not typically associated with upper urinary tract compromise. ${ }^{25}$

This study confirms that voided volume, prolapse stage and the presence of the urethral urodynamics catheter affect urinary flow rates obtained by NIF and PFS. Since flow rates are a critical component of nomograms that are being used for the diagnosis of obstruction, it is important to validate the nomograms for their use in women with prolapse. Future studies comparing flow rates in women with and without prolapse should ideally have similar voided or total bladder volumes for the NIF and PFS and at a minimum report the total and voided volumes.

\section{REFERENCES}

1. Marinkovic SP, Stanton SL. Incontinence and voiding difficulties associated with prolapse. J Urol 2004;171:1021.

2. Nitti VW, Tu LM, Gitlin J. Diagnosing bladder outlet obstruction in women. J Urol 1999;161:1535.

3. Romanzi LJ, Chaikin DC, Blaivas JG. The effect of genital prolapse on voiding. J Urol 1999;161:581.

4. Blaivas JG, Groutz A. Bladder outlet obstruction nomogram for women with lower urinary tract symptomatology. Neurourol Urodyn 2000;19:553.

5. Coates KW, Harris RL, Cundiff GW, et al. Uroflowmetry in women with urinary incontinence and pelvic organ prolapse. Br J Urol 1997;80:217.

6. Abrams PH, Griffiths DJ. The assessment of prostatic obstruction from urodynamic measurements and from residual urine. Br J Urol 1979;51:129.

7. Ko DS, Fenster HN, Chambers $\mathrm{K}$, et al. The correlation of multichannel urodynamic pressure-flow studies and American Urological Association symptom index in the evaluation of benign prostatic hyperplasia. J Urol 1995;154:196.

8. Kuo HC. Clinical prostate score for diagnosis of bladder outlet obstruction by prostate measurements and uroflowmetry. Urology 1999;54:90.

9. Bass JS, Leach GL. Bladder outlet obstruction in women. Prob Urol 1991;5:141.

10. Brubaker L, Cundiff GW, Fine P, et al. Abdominal sacrocolpopexy with Burch colposuspension to reduce urinary stress incontinence. N Engl J Med 2006;354:1557.

11. Diokno AC, Brock BM, Brown MB, et al. Prevalence of urinary incontinence and other urological symptoms in the noninstitutionalized elderly. J Urol 1986;136:1022.

12. Bump RC, Hurt WG, Theofrastous JP, et al. Randomized prospective comparison of needle colposuspension versus endopelvic fascia plication for potential stress incontinence prophylaxis in women undergoing vaginal reconstruction for stage III or IV pelvic organ prolapse. The Continence Program for Women Research Group. Am J Obstet Gynecol 1996;175:326.

13. Barber MD, Kuchibhatla MN, Pieper CF, et al. Psychometric evaluation of 2 comprehensive condition-specific quality of life instruments for women with pelvic floor disorders. Am J Obstet Gynecol 2001;185:1388.

14. Brubaker L, Cundiff G, Fine P, et al. A randomized trial of Colpopexy and Urinary Reduction Efforts (CARE): Design and methods controlled clinical trials 2003;24:629.

15. Nygaard I, Kreder K, Mueller E, et al. Does urethral competance affect urodynamic voiding parameters in women with prolapse? Neurourol Urodyn 2007;26(7):1030-5

16. Defreitas GA, Lemack GE, Zimmern PE. Nonintubated uroflowmetry as a predictor of normal pressure flow study in women with stress urinary incontinence. Urology 2003;62:905.

17. Groutz A, Blaivas JG, Sassone AM. Detrusor pressure uroflowmetry studies in women: Effect of a 7Fr transurethral catheter. J Urol 2000;164:109.

18. Fantl JA, Smith PJ, Schneider V, et al. Fluid weight uroflowmetry in women. Am J Obstet Gynecol 1983;145:1017.

19. Walter S, Olesen KP, Nordling J, et al. Bladder function in urologically normal middle aged females. Scand J Urol Nephrol Suppl 1979;13:249.

20. Haylen BT, Ashby D, Sutherst JR, et al. Maximum and average urine flow rates in normal male and female populations-the liverpool nomograms. $\mathrm{Br}$ J Urol 1989;64:30.

21. Jorgensen JB, Colstrup H, Frimodt-Moller C. Uroflow in women: An overview and suggestions for the future. Int J Urogynecol 1998;9:33.

22. Haylen BT, Law MG, Frazer M, et al. Urine flow rates and residual urine volumes in urogyencology patients. Int J Urogynecol 1999;10:378.

23. Mueller ER, Kenton $\mathrm{K}$, Mahajan S, et al. Urodynamic prolapse reduction alters urethral pressure but not filling or pressure flow parameters. J Urol 2007; $177: 600$.

24. Fitzgerald MP, Kulkarni N, Fenner D. Postoperative resolution of urinary retention in patients with advanced pelvic organ prolapse. Am J Obstet Gynecol 2000;183:1361

25. Beverly CM, Walters MD, Weber AM, Piednantz MR, Ballard LA. Prevalence of hydronephrosis in patients undergoing surgery for pelvic organ prolapse. Obstet Gynecol 1997;90:37. 